\title{
Charting Spiritual Care: Psychiatric and Psychotherapeutic Aspects
}

\author{
Eckhard Frick
}

A sick person's spirituality demands a high level of protection, discretion, and confidentiality on the part of the caregiver. At the same time, the caregiver must provide an open and safe setting in order for a patient to feel comfortable addressing his or her spiritual needs or distress. This interpersonal conflict between disclosure and non-disclosure depends on professional roles, the spiritual care provider's integration into the healthcare team, and systemic pressure emanating from juridical, ethical, or institutional norms, which usually regulate the patient-caregiver relationship.

In addition, the handling of spiritual confidentiality may provoke an intrapersonal conflict in patients, family members, and professional caregivers. Proactively addressing religious and spiritual (r/s) issues has a strong interventional impact on patients. This effect is generally more important than detailed contents gained from spiritual screenings and assessments (Paal et al. 2017):

Oftentimes they need permission to talk about those kinds of issues. Without some signal from the physicians, patients may feel that these topics are not appropriate or welcome (Puchalski and Romer 2000, 130).

When asked about r/s needs or problems, patients may feel ashamed, bothered, surprised, annoyed, or, conversely, satisfied, supported, and acknowledged in their coping efforts. Consequently, documentation should first and foremost reflect the patient's reaction towards the clinician's r/s intervention and to what extent the patient wishes this interaction to be shared within the healthcare team. There is growing evidence that patients want their caregivers to take into account the spiritual dimension of healthcare (Best et al. 2015). Health professionals must, however, respect individual and general boundaries (non-coercive, non-proselytizing, nonneglecting approach). In psychiatry and psychotherapy, patients' spirituality is less

E. Frick $(\square)$

Technical University of Munich, Munich, Germany

e-mail: eckhard.frick@tum.de 
pathologized than in former times. In fact, it is increasingly accepted as a universal dimension to human experience, transcending individual religions. In mental health and other medical fields, r/s may be part of the problem, part of the solution, or both (Pargament et al. 2003, 1346). Consequently, spiritual charting should not only differentiate pathological/negative and resilient/positive coping but should also encompass the patient's r/s healthcare preferences and goals, as well as the role he or she attributes to the healthcare professional. A hermeneutical approach is required both when communicating with the patient and when documenting the case for the healthcare team, i.e. when "translating" the patient's spirituality and sharing it with different team members. Team members must, however, always keep in mind their own r/s and their professional affiliations, as well as their experiences and competencies in this field.

\section{Some Definitions}

Guarding one's boundaries - protecting bodily, emotional, and narrative secrets - is not only a human right but a basic anthropological asset. According to Plessner, a physical, inanimate thing (e.g. the objectified anatomical body: "Körper" in German) is distinguished from other things by a border (demarcation or limit) (Plessner 1928/1975, 126). The living body ("Leib" in German), however, is "boundaryrealising" ("grenzrealisierend") and has a specific, active relation to this boundary. The living body actively negotiates the "radical conflict between the necessity for closure as a physical body and the necessity for openness as an organism" (218).

From birth, an infant, in its nakedness, seems completely exposed to the caregiver's gaze, attitude, and manipulation. Napkins, clothes, and the caregiver's respect provide boundaries which the infant needs in order to thrive. Slowly, the child learns to invest (psychoanalytically speaking: to cathect) in his or her skin, in the physical and emotional boundaries of his or her own living body. During the second year, the child will learn to feel shame when those boundaries are violated, perhaps only by the other's gaze, be it in a real situation or in his or her imagination. Philosophically speaking, the human being is characterized by its eccentric positionality: it is able to relate to its own centre and "step outside his own physical boundaries by means of reflection. This ability allows man to gain distance from his subjective body (Leib) and perceive it as a separate object (Körper)" (Dobeson 2018, 42). Perceiving or imagining the other's gaze, or reflecting upon oneself entails shame, even in the empathetic embarrassment of "Fremdschämen" (feeling ashamed for somebody else).

Confidentiality protects boundaries and also shame, the leading affect (Leitaffekt) expressing eccentric positionality (Merten 2005; Frick 2015). Confidentiality is a shared attitude between patient and caregiver. We use the term secret (i) for everything the patient wants to keep from the knowledge of third parties ("personal secret") and (ii) for the caregiver's confidentiality ("professional secret"). Even matters in no way private may be secret for a person: the term secrecy is different 
from privacy. The professional secret may be individual or collective (shared secret). "This difference lies in the means required for maintaining shared secrets. Benjamin Franklin's remark 'Three may keep a secret if two of them are dead' points up the problem" (Bok 1989, 108). Consequently, multiplying the number of confidants may be necessary for facilitating shared teamwork. Nevertheless this sharing requires strict conditions (Liégeois 2010).

Managing privacy and confidentiality means "navigating between the need for autonomy and the need for connectedness with others" (Petronio et al. 2012), i.e. the interpersonal and intrapersonal conflict between disclosure and non-disclosure.

[...] physicians have potentially two privacy boundaries they regulate with patients. They have their own personal privacy boundaries and judgments about situations where personal disclosures are made to patients. Physicians also serve as guardians or co-owners of their patients' private medical information and are included within the patient's privacy boundary surrounding that information. As co-owners, physicians have a complicated role in that they have to make decisions about issues such as the best treatment plan or a prognosis on the basis of information they gather from tests, and they must deliver that information to the patient. In doing this, physicians often have to judge when to share information with the patient about his/her case, how much to share at any given stage of treatment, what to share, and who else to tell about the patients' confidential medical information (Petronio et al. 2012, 41).

These responsibilities for boundaries apply not only to physicians but also to psychologists and other health professionals. There are three main Communication Privacy Management principles: (1) privacy ownership, (2) privacy control, (3) privacy turbulence.

Thus, needing to trust a physician to gain health care can motivate a patient to reveal information. For the patient, granting access likely includes judging risks and benefits of allowing complete or partial access. Nevertheless, when the patient discloses information, the physician becomes an authorized co-owner or guardian and, with that, comes an implied expectation that the physician will "care" for the information in the way the patient expects. If these expectations about responsible treatment of the information are violated, privacy turbulence [principle \#3, E.F.] results in the physician-patient relationship (Petronio et al. 2012, 42).

While confidentiality concerns the helping relationship, testimonial privilege refers to investigative authorities. It "protects information possessed by spouses or members of the clergy or lawyers against coerced revelations in court" (Bok 1989, 119).

Not only from a theological but also from an anthropological perspective, it is important to differentiate secret and mystery. In spoken English, we may use both words as synonyms: we unlock the mystery/secret of someone or something. However, the Cambridge Dictionary defines secret as "a piece of information that is only known by one person or a few people and should not be told to others" and mystery as "something strange or not known that has not yet been explained or understood." Obviously, a secret is concealed by a person and disappears after disclosure. Conversely, the personal origin and the conditions of revealing a mystery remain opaque. Theologically speaking, revelation does not "unlock" but confirms and respects the hidden (absconditus) God. Analogically, knowing the other person 
in a helping or loving relationship does not eliminate his or her mystery, but deepens it: "As a being exposed to the world, man is concealed to himself - homo absconditus. This concept, originally attributed to the impenetrable essence of God, corresponds to the nature of man" (Plessner 1969, 508).

\section{Systemic Barriers and Facilitators}

Institutional and juridical norms provide a framework for dealing with confidentiality, preserving patients' rights and balancing caregivers' rights and obligations in this field. In their daily patient work, healthcare professionals continue to be challenged by data protection, data privacy, and the duty of secrecy/obligation to preserve confidentiality. In psychiatry and psychotherapy, data are often more sensitive than in other medical fields. A law student, e.g., may be afraid of being disadvantaged in his or her legal career if a psychotherapeutic consultation is documented.

As far as spiritual care is concerned, charting depends on the spiritual care model observed in a given institutional context, e.g.:

(i) "Spiritual care is not the hospital's business" (Pujol et al. 2016) (French laicism): in public hospitals, spiritual care is delegated to chaplains who work independently of the caring team.

(ii) The board-certified chaplain has the right and the obligation to contribute to electronic health records or other documentation systems (Johnson et al. 2016).

(iii) According to the WHO's definition, palliative care consists of "prevention and relief of suffering by means of early identification and impeccable assessment and treatment of pain and other problems, physical, psychosocial and spiritual" (http://www.who.int/cancer/palliative/definition/en/). This systemic integration of spiritual care is groundbreaking for other medical fields.

(iv) In psychiatry and psychotherapy, the paradigm of pathologizing religion and spirituality is more and more being replaced by efforts to bridge the "religiosity gap' between patients, who are more likely to be religious, and psychiatrists, who are more likely to be atheist or agnostic" (Cook and Sims 2018).

In scenario (i), there is neither a need nor an obligation (on the contrary: there is legal prohibition) to take into account spiritual care in the clinical context, at least officially. However, as in other European contexts, spiritual care is an increasingly important subject for "secularised" medicine (Cook et al. 2011) in France (Frick 2006) and in the highly secularized Swiss Canton of Geneva (Huguelet 2017). The integration of a board-certified chaplain (ii) is somewhat the opposite of French secularism. This integration may impose a certain adaptation or "medicalisation" on the chaplain, perhaps putting at risk the independence he or she has in (i). Model (iii) is unique and exemplary, at the same time, for this book's scope: in palliative care, charting encompasses the whole unit of care: patients, families, and caregivers who work to improve the quality of life in an end-of-life context. What does this model mean for psychiatry and psychotherapy (iv)? Not only the World Psychiatric 
Organization (Moreira-Almeida et al. 2015) but also national psychiatric organizations, e.g. in Britain (Royal College of Psychiatrists 2013) and Germany (Utsch et al. 2017), strongly recommend fostering spiritual and religious sensitivity among health professionals in psychiatry and psychotherapy.

Liefbroer et al. review two questions addressed in literature (Liefbroer et al. 2019): (i) Who should provide spiritual care - all health professionals as generalists $(G)$ or chaplains as specialists $(S)$ ?; (ii) What is the role of caregivers' spirituality when providing spiritual care? - the universalist $(U)$ stance focuses on generic, universal aspects of spiritual care provision and underlines the importance of caring for all patients regardless of the professional caregiver's or receiver's particular spiritual background. Conversely, the particularist stance $(P)$ highlights the importance of caregivers' own spiritual orientation in spiritual caregiving. Four combinations are possible: $G U, G P, S U$, and $S P$. Evidently, charting and documentation will be different according to these modes: In $G U$, every team member has a spiritual care responsibility, regardless of personal convictions: a common language for communicating will be necessary. In $G P$, differences between personal convictions in spirituality need to be bridged. In $S U$ and $S P$, spiritual care is delegated to a specialist (in general, the chaplain). In the classical confessional mode $(S P)$, there will be a tendency for non-disclosure. The $S U$-mode depends on the institutional conditions already mentioned.

\section{Code Languages}

Professional caregivers are used to specific codes, depending on profession and subprofession, such as internal medicine, surgery, or psychiatry. These code languages are identified empirically, i.e. distinguishing code differences between (sub-)professions is a descriptive, not a normative, judgement. Different professions, e.g. chaplains and nurses, may desire a "universal code" for communicating about patients" spiritual needs and preferences. This desire and an effort to understand the other profession's code may facilitate the sharing of responsibilities. Code differences will, however, not disappear completely. Notably, a complete "totalisation" of languages is not desirable. Furthermore, these codes (often in acronyms, abbreviations, and idioms) are widely used for inside-communication within a given specialty and far less for inter-specialty communication. Palliative care (iii) shares a general outcome-orientation with medical and nursing care. However, as opposed to other medical fields, the outcome here is quality of life, not the elimination of a disease and its roots.

It is true that there is a plethora of studies examining medical and especially psychiatric outcomes in association with religious and spiritual behaviours or activities. Religious involvement is (weakly or moderately) correlated with:

- Purpose and meaning in life

- Higher self-esteem 
- Adaptation to bereavement

- Greater social support and less loneliness

- Lower rates of depression and faster recovery from depression

- Lower rates of suicide and fewer positive attitudes towards suicide

- Less anxiety

- Less psychosis and fewer psychotic tendencies

- Lower rates of alcohol and drug use and abuse

- Less delinquency and criminal activity

- Greater marital stability and satisfaction (Koenig et al. 2001, 228)

Health insurances could conclude that a bonus should be given to all insured persons who pray and frequent churches, synagogues, or mosques.

Spirituality, however, is not outcome-oriented. Spiritual codes use words of the health and healing sphere, but in a metaphorical sense. The core concepts of spirituality are the search for the sacred and transcendent. "Hope," e.g., may mean obtaining a negative result in cancer diagnostics. The same word "hope" in the spiritual (transcendent) meaning goes beyond a medically defined outcome, even in unfavourable disease evaluation or in the end-of-life situation. Other examples for different codings are "meaning of life" and "purpose." A psychotherapeutic goal and outcome could be re-establishing a "healthy" meaning and purpose attribution, e.g. in treating depression or narcissistic personality disorder.

Conversely, spirituality is "indifferent" to all those outcomes, as Ignatius of Loyola formulates in his Spiritual Exercises (\#23): “[...] so that, on our part, we want not health rather than sickness, riches rather than poverty, honour rather than dishonour, long rather than short life" (Ignatius 1548/1914).

This "indifference" in spiritual coding accepts both meaning in life and meaninglessness, absurdity, grief, and lamentation. These phenomena are not pathology codes. At the same time, spirituality should not be used as a kind of "meaning transplant" towards the suffering person.

In some clinical fields such as palliative care, psychiatry, and psychotherapy, there is a landscape of medical and spiritual codings. We treat diseases and symptoms of body and soul. And even when we "treat the soul" ("mental diseases") we know that with "soul" we name an openness towards transcendence, an openness we cannot "treat" or influence, but only respect.

In certain clinical fields with strong outcome-orientation, e.g. in critical care, chaplains may have a language and a perspective quite different from other caregivers. When they observe and resume their work with terms such as "compassionate presence" (Lee et al. 2017), this may be difficult to understand for other team members and insufficient to illuminate patients' individual stories.

Raffay et al. highlight the diversity of patients' and caregivers' spiritual aspirations (Raffay et al. 2016). They report, nevertheless, the salient principle of coproduction ("everyone has a vital contribution to make and brings people who use mental health services, carers, and staff together on equal terms"), which spiritual care encompasses. Furthermore, Heffernan et al.'s review suggests that proactively taking a spiritual history is useful in psychiatry (Heffernan et al. 2014). 


\section{Possible Interpersonal Conflicts}

Given an increasingly diverse religious landscape, health professionals will encounter challenging $\mathrm{r} / \mathrm{s}$ conversations and new challenges in communication privacy management, as far as the patient's boundaries and their own boundaries are concerned (Canzona et al. 2015). In our own programme for training general practitioners in taking a spiritual history (Straßner et al. 2019) we insist on the capacity to navigate between disclosure and non-disclosure and to respect both the physician's and the patient's boundaries. Furthermore, physicians learn to document what they have discussed when taking the spiritual history. In an interprofessional approach, medical assistants are trained to accompany patients' spiritual evolution in their routine contact.

In 2008, Harold Koenig suggested that good psychiatric practice should include the taking of a spiritual history (Koenig 2008). Koenig's position provoked a vivid controversy in UK psychiatry: This included the critique that spiritual care offers breach proper professional boundaries, that they lack respect for those who reject transcendence, that they open the door to proselytizing, and that they risk causing harm (e.g. to patients with religious delusions). This controversy may be called a conflict between spirituality and secularity in psychiatry (Koenig 2008). In his statement, Cook refers to Taylor's differentiation between a naive ("porous") and a "buffered self” (Taylor 2007):

In the first condition, the actions of spirits or 'magical' forces is [sic!] sensed as something we experience, as we can the wind, or the elements, or human or animal aggression. The self is 'porous', and one can be to different degrees 'taken over' by such 'magical' agencies. By contrast, for the 'buffered' self, the agency here has to be 'occult', that is, it is something one might accept as a hypothetical cause of events which would themselves be 'naïvely' experienced, such as my falling ill, or suddenly losing a capacity I counted on (Taylor 2010, 415).

For Taylor, the buffered secular self entails "a mutual fragilisation of different positions, and the resulting sense of optionality." The buffered self is cut off from transcendence, restricted to an immanent frame.

Liégeois recommends a model of "conditional shared professional secrecy" (Liégeois 2010). His spiritual care model is the specialist-particular/universal ( $S$ - $P$ / $U$ ). Nevertheless, for practical and ethical reasons, his arguments are helpful for other spiritual care models, too. Not very different from the communication privacy management model (Petronio et al. 2012; Canzona et al. 2015), he addresses the ethical, juridical, and spiritual conflict between confidentiality/non-disclosure and team communication/disclosure and formulates five conditions: (1) the care professionals participate in a clearly defined and identifiable team or network, (2) they perform a common task in care, (3) they are bound by the duty of professional secrecy, (4) they engage in a consultation to ask the patient's informed consent, and (5) they apply the filter of relevance.

The filter of relevance is particularly important not only for team meetings and oral communication, but also for charting, for electronic documentation, etc. The 
spiritual caregiver has to choose information of clinical interest. He/she may also check with the patient which information he/she wishes to be disclosed to the caring team.

\section{Possible Intrapersonal Conflicts}

Coping with conflicts, navigating between and balancing spiritual confidentiality and disclosure may provoke shame in an interpersonal or group setting, e.g. when the team or a reporting team member experiences voyeurism, perhaps in an ambivalence between avoiding and desiring it.

As a matter of course, shame is still more salient when a person such as the patient is vulnerable. In a dual relationship, shame may be tolerated or it may even permit a certain intimacy, e.g. in basic nursing acts or in a respectful medical examination.

As we saw, the human being is "boundary-realising" and may shamefully perceive the fragility of its body and soul. Respecting shame is of immense importance not only in a romantic relationship but also in every helping or therapeutical professional relationship.

When boundaries are threatened or need protection, shame arises: this is particularly true for the health professionals' and patients' boundaries in the sphere of religion and spirituality. According to Charles Taylor, the secular self loses its "porosity" and protects itself by "buffering" and by multiplying spiritual options (Taylor 2007). When the patient's spiritual quest is not only listened to (in a conversation with his or her doctor), but also communicated within the caring team or even documented in a chart, this may provoke "porosity-anxiety" on the part of the patient.

\section{Mystery Is More Important than Mastery}

Contemporary healthcare must get to grips with numerous problems, which humanity has faced for centuries without the hope of healing or even alleviation. To this end, it is important that our intention is to understand a sick person and to share this understanding in the caring team.

What the paediatrician and psychoanalyst Winnicott calls "incommunicado" (Winnicott 1960/1990, 186) is, anthropologically speaking, the mystery of the human being (Plessner 1969). In this contribution, I have reflected upon the conflicts between non-disclosure and disclosure in spiritual care, and upon a responsible boundary management. The ultimate boundary protects the self's core, the incommunicado. 


\section{References}

Best, Megan, Phyllis Butow, and Ian Olver. 2015. Do patients want doctors to talk about spirituality? A systematic literature review. Patient Education and Counseling 98 (11): 1320-1328. https://doi.org/10.1016/j.pec.2015.04.017.

Bok, Sissela. 1989. Secrets: On the ethics of concealment and revelation. New York: Vintage.

Canzona, Mollie Rose, Emily Bylund Peterson, Melinda M. Villagran, and Dean A. Seehusen. 2015. Constructing and communicating privacy boundaries: How family medicine physicians manage patient requests for religious disclosure in the clinical interaction. Health Communication 30 (10): 1001-1012. https://doi.org/10.1080/10410236.2014.913222.

Cook, Christopher C.H., Andrew Powell, Andrew Sims, and Sarah Eagger. 2011. Spirituality and secularity: Professional boundaries in psychiatry. Mental Health, Religion and Culture 14 (1): $35-42$.

Cook, Christopher C.H., and Andrew Sims. 2018. Spiritual aspects of management. In Textbook of cultural psychiatry, ed. Dinesh Bhugra and Kamaldeep Bhui, 472-481. Cambridge: Cambridge University Press.

Dobeson, Alexander. 2018. Between openness and closure: Helmuth plessner and the boundaries of social life. Journal of Classical Sociology 18 (1): 36-54. https://doi.org/10.1177/14687 $95 \times 17704786$.

Frick, Eckhard. 2006. Peut-on quantifier la spiritualité? Un regard d'outre-Rhin à propos de l'actuelle discussion française sur la place du spirituel en psycho-oncologie. Revue Francophone de Psycho-Oncologie 5 (3): 160-164.

- 2015. Psychosomatische Anthropologie. Ein Lern- und Arbeitsbuch für Unterricht und Studium (2. Auflage). Stuttgart: Kohlhammer.

Heffernan, Suzanne, Sandra Neil, and Stephen Weatherhead. 2014. Religion in inpatient mental health: A narrative review. Mental Health Review Journal 19 (4): 221-236. https://doi. org/10.1108/MHRJ-09-2014-0035.

Huguelet, Philippe. 2017. Psychiatry and religion: A perspective on meaning. Mental Health, Religion \& Culture 20 (6): 567-572. https://doi.org/10.1080/13674676.2017.1377956.

Ignatius. 1548/1914. The spiritual exercises of St. Ignatius of Loyola (translated from the autograph by Elder Mullan, s.j.). New York: P.J. Kenedy \& Sons.

Johnson, Rebecca, M. Jeanne Wirpsa, Lara Boyken, Matthew Sakumoto, George Handzo, Abel Kho, and Linda Emanuel. 2016. Communicating chaplains' care: Narrative documentation in a neuroscience-spine intensive care unit. Journal of Health Care Chaplaincy 22 (4): 133-150. https://doi.org/10.1080/08854726.2016.1154717.

Koenig, Harold G. 2008. Religion and mental health: What should psychiatrists do? Psychiatric Bulletin 32: 201-203.

Koenig, Harold G., Michael E. McCullough, and David B. Larson. 2001. Handbook of religion and health. Oxford: Oxford University Press.

Lee, Brittany M., Farr A. Curlin, and Philip J. Choi. 2017. Documenting presence: A descriptive study of chaplain notes in the intensive care unit. Palliative \& Supportive Care 15 (2): 190-196. https://doi.org/10.1017/S1478951516000407.

Liefbroer, Anke I., R. Ruard Ganzevoort, and Erik Olsman. 2019. Addressing the spiritual domain in a plural society: What is the best mode of integrating spiritual care into healthcare? Mental Health, Religion \& Culture: 1-17. https://doi.org/10.1080/13674676.2019.1590806.

Liégeois, Axel. 2010. Le conseiller spirituel et le partage d'informations en soins de santé. Un plaidoyer pour un secret professionnel partagé. Counselling and Spirituality / Counseling et spiritualité 29 (2): 85-97.

Merten, Jörg. 2005. Facial microbehavior and the emotional quality of the therapeutic relationship. Psychotherapy Research 15 (3): 325-333. https://doi.org/10.1080/10503300500091272.

Moreira-Almeida, Alexander, Avdesh Sharma, Bernard Janse van Rensburg, Peter J. Verhagen, and Christopher C.H. Cook. 2015. WPA Position statement on spirituality and religion in psychiatry. 
http://www.wpanet.org/uploads/Position_Statement/WPA\%20position\%20Spirituality\%20 statement\%20final\%20version_rev2\%20on\%20Spirituality.pdf, access 8.5.2016.

Paal, Piret, Eckhard Frick, Traugott Roser, and Guy Jobin. 2017. Expert discussion on taking a spiritual history. Journal of Palliative Care 32 (1): 19-25. https://doi.org/ $10.1177 / 0825859717710888$.

Pargament, Kenneth I., Brian J. Zinnbauer, Allie B. Scott, Eric M. Butter, Jill Zerowin, and Patricia Stanik. 2003. Red flags and religious coping: Identifying some religious warning signs among people in crisis. Journal of Clinical Psychology 59 (12): 1335-1348.

Petronio, Sandra, Mark J. Dicorcia, and Ashley Duggan. 2012. Navigating ethics of physicianpatient confidentiality: A communication privacy management analysis. The Permanente Journal 16 (4): 41-45. https://doi.org/10.7812/tpp/12-042.

Plessner, Helmuth. 1928/1975. Die Stufen des Organischen und der Mensch. Einleitung in die philosophische Anthropologie. Berlin: De Gruyter.

_. 1969. De homine abscondito. Social Research 36 (4): 497-509.

Puchalski, Christina M., and Anna L. Romer. 2000. Taking a spiritual history allows clinicians to understand patients more fully. Journal of Palliative Medicine 3 (1): 129-137.

Pujol, Nicolas, Guy Jobin, and Sadek Beloucif. 2016. 'Spiritual care is not the hospital's business': A qualitative study on the perspectives of patients about the integration of spirituality in healthcare settings. Journal of Medical Ethics 62 (11): 733-737. https://doi.org/10.1136/ medethics-2016-103565.

Raffay, Julian, Emily Wood, and Andrew Todd. 2016. Service user views of spiritual and pastoral care (chaplaincy) in NHS mental health services: A co-produced constructivist grounded theory investigation. BMC Psychiatry 16: 200-200. https://doi.org/10.1186/s12888-016-0903-9.

Royal College of Psychiatrists. 2013. Recommendations for psychiatrists on spirituality and religion, position statement PS03/2013.. Royal College of Psychiatrists.

Straßner, Cornelia, Eckhard Frick, Gabriele Stotz-Ingenlath, Nicola Buhlinger-Göpfarth, Joachim Szecsenyi, Johannes Krisam, Friederike Schalhorn, Jan Valentini, Regina Stolz, and Stefanie Joos. 2019. Holistic care program for elderly patients to integrate spiritual needs, social activity, and self-care into disease management in primary care (HoPES3): Study protocol for a cluster-randomized trial. Trials 20 (1): 364-364. https://doi.org/10.1186/s13063-019-3435-z.

Taylor, Charles. 2007. A secular age. Cambridge, MA: Belknap Press of Harvard University Press. 2010. Challenging issues about the secular age. Modern Theology 26 (3): 404-416.

Utsch, Michael, Ulrike Anderssen-Reuster, Eckhard Frick, Werner Gross, Sebastian Murken, Meryam Schouler-Ocak, and Gabriele Stotz-Ingenlath. 2017. Empfehlungen zum Umgang mit Religiosität und Spiritualität in Psychiatrie und Psychotherapie. Spiritual Care 6 (1): 141-146. https://doi.org/10.1515/spircare-2016-0220.

Winnicott, Donald Woods. 1960/1990. The maturational process and the facilitating environment. London: Karnac Books \& The Institute of Psychoanalysis.

Open Access This chapter is licensed under the terms of the Creative Commons Attribution 4.0 International License (http://creativecommons.org/licenses/by/4.0/), which permits use, sharing, adaptation, distribution and reproduction in any medium or format, as long as you give appropriate credit to the original author(s) and the source, provide a link to the Creative Commons license and indicate if changes were made.

The images or other third party material in this chapter are included in the chapter's Creative Commons license, unless indicated otherwise in a credit line to the material. If material is not included in the chapter's Creative Commons license and your intended use is not permitted by statutory regulation or exceeds the permitted use, you will need to obtain permission directly from the copyright holder.

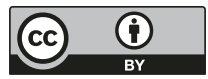

